\title{
An effect of herbicides and their mixtures on potato yielding and efficacy in potato crop
}

\section{Wpływ herbicydów i ich mieszanin na plonowanie i skuteczność chwastobójczą w uprawie ziemniaka}

\author{
Iwona Mystkowska ${ }^{1 *}$, Krystyna Zarzecka $^{2}$, Alicja Baranowska ${ }^{1}$, Marek Gugała ${ }^{2}$
}

\begin{abstract}
Summary
The research was carried out to evaluate the effectiveness of selected herbicides and their mixtures in potato crops. The presented results are from the field experiments conducted in the years 2008-2010. The experiment was set up as a split-plot design with three replicates. The factors examined in the experiment included three potato cultivars - Satina, Tajfun, Cekin, and five weed control methods of pesticide applications, four with the use of herbicides and their mixtures: with a mixture: herbicides Command 480 EC, Command 480 EC + Afalon Dyspersyjny 450 SC, Stomp 400 SC, Stomp 400 SC + Afalon Dyspersyjny 450 SC and without herbicides (control object). The ratio of dry mass of weeds destroyed before harvesting the tubers variend depending on the method of weed control, and ranged from $34.4 \%$ to $68.3 \%$. The mixture of herbicide Command 480 EC + Afalon Dyspersyjny provided the highest effectivenes.
\end{abstract}

Key words: herbicides; yield; weed infestation; potato

\section{Streszczenie}

Celem badań była ocena skuteczności chwastobójczej wybranych herbicydów i ich mieszanin na plantacji ziemniaka. Wyniki badań pochodzą z doświadczeń polowych przeprowadzonych w latach 2008-2010. Eksperyment założono w układzie split-plot, jako dwuczynnikowy w trzech powtórzeniach. Badanymi czynnikami były trzy odmiany ziemniaka - Satina, Tajfun, Cekin, a także pięć sposobów pielęgnacji - cztery z użyciem herbicydów i ich mieszanin: Command 480 EC, Command 480 EC + Afalon Dyspersyjny 450 SC, Stomp 400 SC, Stomp 400 SC + Afalon Dyspersyjny 450 SC oraz bez herbicydów (obiekt kontrolny). Procent zniszczenia suchej masy chwastów przed zbiorem bulw był zróżnicowany w zależności od sposobów pielęgnacji i wynosił od 34,4\% do 68,3\%. Największą skuteczność chwastobójczą stwierdzono na obiekcie opryskiwanym mieszaniną herbicydów Command 480 EC + Afalon Dyspersyjny.

Słowa kluczowe: herbicydy; plon; zachwaszczenie; ziemniak

\footnotetext{
${ }^{1}$ Państwowa Szkoła Wyższa im. Papieża Jana Pawła II w Białej Podlaskie Katedra Nauk Technicznych

Sidorska 95/97, 21-500 Biała Podlaska

${ }^{2}$ Uniwersytet Przyrodniczo-Humanistyczny w Siedlcach

Katedra Agrotechnologii

Prusa 14, 08-110 Siedlce

*corresponding author: imystkowska@op.pl
} 


\section{Wstęp / Introduction}

Wielkość i jakość plonu ziemniaka zależą od wielu czynników agrotechnicznych i środowiskowych (Krzysztofik i wsp. 2009; Rębarz i Borówczak 2009; Szewczuk 2009; Gugała i wsp. 2010). Jednym z ważniejszych jest właściwa pielęgnacja skutecznie ograniczająca zachwaszczenie (Zarzecka i wsp. 2014). Chwasty w uprawie ziemniaka wykazują największą szkodliwość w dwóch krytycznych okresach, tj. na początku i pod koniec wegetacji. Ze wszystkich agrofagów cechują się największą potencjalną zdolnością do obniżania plonów średnio o 34\% (Praczyk i Skrzypczak 2011). Zachwaszczenie plantacji ziemniaka wymusza potrzebę stosowania różnych metod pielęgnacji, a właściwy dobór herbicydów zapewnia dużą efektywność w zwalczaniu roślinności segetalnej (Pytlarz-Kozicka 2002).

Celem badań była ocena skuteczności chwastobójczej wybranych herbicydów i ich mieszanin oraz oddziaływanie na plon bulw ziemniaka.

\section{Materiały i metody / Materials and methods}

Badania przeprowadzono w latach 2008-2010 w Rolniczej Stacji Doświadczalnej Zawady należącej do Uniwersytetu Przyrodniczo-Humanistycznego w Siedlcach. Eksperyment założono metodą losowanych podbloków, jako dwuczynnikowy w trzech powtórzeniach, na glebie zaliczanej do kompleksu żytniego bardzo dobrego, klasy IVa. Czynnikiem pierwszego rzędu były trzy odmiany ziemniaka jadalnego: Cekin, Satina, Tajfun, a drugiego rzędu pięć sposobów pielęgnacji: 1. obiekt kontrolny pielęgnacja mechaniczna do i po wschodach roślin ziemniaka, tj. do wschodów dwukrotne obredlanie i jednokrotne obredlanie $\mathrm{z}$ bronowaniem, a po wschodach dwukrotne obredlanie, bez bronowania, 2. pielęgnacja mechaniczno-chemiczna, tj. do wschodów obredlanie połączone $\mathrm{z}$ bronowaniem, a około 7 dni przed wschodami opryskiwanie herbicydem Command $480 \mathrm{EC} 0,2 \mathrm{dm}^{3} / \mathrm{ha}$, 3. pielęgnacja mechaniczno-chemiczna, tj. do wschodów obredlanie połączone $\mathrm{z}$ bronowaniem, a około 7 dni przed wschodami opryskiwanie mieszaniną herbicydów Command 480 EC $0,2 \mathrm{dm}^{3} /$ ha + Afalon Dyspersyjny $450 \mathrm{SC} 1,0 \mathrm{dm}^{3} / \mathrm{h}, 4$. pielęgnacja mechaniczno-chemiczna, tj. do wschodów obredlanie połączone $\mathrm{z}$ bronowaniem, a około 7 dni przed wschodami opryskiwanie herbicydem Stomp $400 \mathrm{SC} 3,5 \mathrm{dm}^{3} / \mathrm{ha}$, 5. pielęgnacja mechaniczno-chemiczna, tj. do wschodów obredlanie połączone $\mathrm{z}$ bronowaniem, a około 7 dni przed wschodami opryskiwanie mieszaniną herbicydów Stomp $400 \mathrm{SC} 3,5 \mathrm{dm}^{3} /$ ha + Afalon Dyspersyjny $450 \mathrm{SC} 1,0 \mathrm{dm}^{3} /$ ha. Herbicydy i ich mieszaniny aplikowano tuż przed wschodami roślin ziemniaka. Jesienią stosowano nawóz naturalny - obornik $w$ dawce 25,0 t/ha $i$ nawozy mineralne fosforowo-potasowe w ilości $\mathrm{P}-44,0 \mathrm{~kg} / \mathrm{ha}$ (superfosfat potrójny $46 \%$ ) i K - 124,5 kg/ha (sól potasowa 60\%), a wiosną przed zabiegami uprawowymi nawożenie azotowe (saletra amonowa 34\%) w dawce $100 \mathrm{~kg} \mathrm{~N} / \mathrm{ha}$. Bulwy ziemniaka sadzono ręcznie w drugiej dekadzie kwietnia, w rozstawie rzędów wynoszącej $67 \mathrm{~cm}$ i odległości w rzędzie $37 \mathrm{~cm}$. W celu porównania skuteczności badanych sposobów pielęgnacji określono stopień zachwaszczenia łanu ziemniaka. Analizę zachwaszczenia poletek przeprowadzono w dwóch terminach: 2-3 tygodnie po zastosowaniu herbicydów i ich mieszanin (przed zwarciem rzędów) i pod koniec wegetacji (1-2 tygodnie przed zbiorem bulw). Oznaczenia wykonano metodą ramkowo-wagową i określono: powietrznie suchą masę chwastów na powierzchni $1 \mathrm{~m}^{2}$ przy użyciu ramki o wymiarach $150 \mathrm{~cm} \times 33,4 \mathrm{~cm}$ oraz plon frakcji handlowej. Skuteczność chwastobójczą (udział liczby zniszczonych chwastów) wyrażano w procentach $\mathrm{W}$ stosunku do obiektu kontrolnego pielęgnowanego tylko mechanicznie, zgodnie $\mathrm{z}$ metodyką podaną przez Badowskiego i wsp. (2001). Po zbiorze dokonano podziału bulw na frakcje i za plon bulw frakcji handlowej przyjęto masę bulw o średnicy powyżej $35 \mathrm{~mm}$ przeliczoną na 1 ha (Roztropowicz i wsp. 1999; Rozporządzenie 2003). Wyniki badań opracowano statystycznie za pomocą analizy wariancji, a istotność różnic testowano za pomocą wielokrotnych przedziałów Tukeya.

Do charakterystyki warunków pogodowych panujących podczas wegetacji ziemniaka wykorzystano sumy opadów,

Tabela 1. Warunki pogodowe podczas wegetacji ziemniaka (2008-2010)

Table 1. Weather conditions during of potato vegetation (2008-2010)

\begin{tabular}{|c|c|c|c|c|c|c|c|}
\hline \multirow{2}{*}{$\begin{array}{l}\text { Lata } \\
\text { Years }\end{array}$} & \multicolumn{6}{|c|}{ Miesiące - Months } & \multirow{2}{*}{$\begin{array}{l}\text { kwiecień - wrzesień } \\
\text { April - September }\end{array}$} \\
\hline & $\begin{array}{c}\text { kwiecień } \\
\text { April }\end{array}$ & $\begin{array}{l}\text { maj } \\
\text { May }\end{array}$ & $\begin{array}{l}\text { czerwiec } \\
\text { June }\end{array}$ & $\begin{array}{l}\text { lipiec } \\
\text { July }\end{array}$ & $\begin{array}{c}\text { sierpień } \\
\text { August }\end{array}$ & $\begin{array}{l}\text { wrzesień } \\
\text { September }\end{array}$ & \\
\hline 1 & 2 & 3 & 4 & 5 & 6 & 7 & 8 \\
\hline \multicolumn{8}{|c|}{ Temperatura powietrza - Air temperature $\left[{ }^{\circ} \mathrm{C}\right]$} \\
\hline 2008 & 9,1 & 12,7 & 17,4 & 18,4 & 18,5 & 12,2 & 14,7 \\
\hline 2009 & 10,3 & 12,9 & 15,7 & 19,4 & 17,7 & 14,6 & 15,1 \\
\hline 2010 & 8,9 & 14,0 & 17,4 & 21,6 & 19,8 & 11,8 & 15,6 \\
\hline $\begin{array}{c}\text { Średnia } \\
\text { wieloletnia } \\
\text { Multiyear mean } \\
(1987-2000)\end{array}$ & 7,8 & 12,5 & 17,2 & 19,2 & 18,5 & 13,1 & 14,7 \\
\hline
\end{tabular}




\begin{tabular}{|c|c|c|c|c|c|c|c|}
\hline 1 & 2 & 3 & 4 & 5 & 6 & 7 & 8 \\
\hline \multicolumn{8}{|c|}{ Opady - Rainfalls [mm] } \\
\hline 2008 & 28,2 & 85,6 & 49,0 & 69,8 & 75,4 & 63,4 & 371,4 \\
\hline 2009 & 8,1 & 68,9 & 145,2 & 26,4 & 80,9 & 24,9 & 354,4 \\
\hline 2010 & 10,7 & 93,2 & 62,6 & 77,0 & 106,3 & 109,9 & 459,7 \\
\hline $\begin{array}{l}\text { Suma wieloletnia } \\
\text { Multiyear sum } \\
(1987-2000)\end{array}$ & 38,6 & 44,1 & 52,4 & 49,8 & 43,0 & 47,3 & 275,2 \\
\hline \multicolumn{8}{|c|}{ Współczynnik hydrotermiczny Sielianinowa - Sielianinov’s hydrothermic coefficient } \\
\hline 2008 & 1,04 & 2,18 & 0,94 & 1,25 & 1,36 & 1,73 & 1,39 \\
\hline 2009 & 0,26 & 1,72 & 3,08 & 0,44 & 1,48 & 0,57 & 1,28 \\
\hline 2010 & 0,40 & 2,14 & 1,20 & 1,15 & 1,74 & 3,10 & 1,61 \\
\hline
\end{tabular}

Wartość współczynnika - Coefficient value (Bac i wsp. 1998)

do 0,50 silna posucha - strong drought

$0,51-0,69$ posucha - drought

$0,70-0,99$ słaba posucha - weak drought

$\geq 1$ brak posuchy - fault drought

średnią temperaturę powietrza oraz współczynnik hydrotermiczny Sielianinowa i przedstawiono je w tabeli 1 . W 2008 roku opady były większe niż w okresie wieloletnim, a ich rozkład był korzystny dla wzrostu i rozwoju ziemniaka, natomiast temperatury powietrza były podobne, jak w okresie wieloletnim. Rok 2009 odznaczał się nierównomiernie rozłożonymi opadami i wyższymi temperaturami powietrza, a współczynnik hydrotermiczny wahał się w szerokich granicach od 0,26 do 3,08. Okres wegetacji ziemniaka w 2010 roku był najcieplejszy, charakteryzował się dużą wilgotnością, a współczynnik hydrotermiczny w miesiącach gromadzenia plonu (czerwiec, lipiec, sierpień) był stabilny.

\section{Wyniki i dyskusja / Results and discussion}

Fernandez-Quintanilla i wsp. (2008) stwierdzili, że spośród agrofagów chwasty cechują się największą potencjalną ,zdolnością" ograniczania plonów, gdyż zmniejszają je średnio o $34 \%$, natomiast szkodniki o $18 \%$, a choroby o $16 \%$. Powietrznie sucha masa chwastów przed zwarciem rzędów roślin ziemniaka i przed zbiorem bulw zależała istotnie od sposobów odchwaszczania, odmian i lat badań (tab. 2, 3). Istotne różnice zanotowano pomiędzy obiektem kontrolnym a pozostałymi sposobami odchwaszczania oraz pomiędzy obiektami z pojedynczym herbicydem i mieszaniną dwóch herbicydów w obydwu terminach oznaczeń. Najmniejszą średnią wartość powietrznie suchej masy chwastów zarówno przed zwarciem rzędów, jak i zbiorem bulw ziemniaka stwierdzono na obiekcie 3. pielęgnowanym do wschodów mechanicznie, a po wschodach opryskiwanym mieszaniną herbicydów Command $480 \mathrm{EC}+$ Afalon Dyspersyjny 450 SC. $\mathrm{Z}$ uprawianych odmian najbardziej zachwaszczona zarówno przed zwarciem rzędów, jak i przed zbiorem bulw była odmiana Satina, która okazała się mało konkurencyjna $\mathrm{W}$ stosunku do chwastów ze względu na łodygowy pokrój krzaka. Istotne różnice w powietrznie suchej masie chwastów zanotowano także w poszczególnych latach uprawy. Najbardziej zachwaszczone poletka ziemniaczane były w 2010 roku, w którym opady i temperatura powietrza były największe w odniesieniu do pozostałych lat badań.

Z przeprowadzonych badań wynika, że zniszczenie powietrznie suchej masy chwastów było większe pod koniec wegetacji niż przed zwarciem rzędów ziemniaka (tab. 4, 5). Skuteczność chwastobójczą najbardziej różnicowały zabiegi mechaniczno-chemiczne z użyciem herbicydów zastosowanych do pielęgnacji łanu ziemniaka. W obydwu terminach oznaczania zachwaszczenia najbardziej skuteczna okazała się mieszanina herbicydów Command $480 \mathrm{EC}+$ Afalon Dyspersyjny 450 SC. Na początku wegetacji zniszczenie masy chwastów na obiekcie 3. wynosiło od 48,3 do $76,9 \% \mathrm{w}$ analizowanych latach badań, a zależnie od odmiany od 58,2 do 71,6\% (tab. 4). Przed zbiorem bulw skuteczność zwalczania chwastów na tym obiekcie wynosiła odpowiednio od 52,4 do 74,7\% i od 67,2 do 73,0\% (tab. 5). Najlepszy efekt chwastobójczy w prowadzonym doświadczeniu po zastosowaniu zabiegów mechaniczno-chemicznych otrzymano w 2010 roku (średnio 62,3\% zniszczenia), który był najcieplejszy i charakteryzował się dużą wilgotnością, a najgorszy efekt chwastobójczy - w sezonie 2008 (średnio 35,0\%), w którym opady były większe niż w okresie wieloletnim.

Plon frakcji handlowej bulw zależał istotnie od sposobów odchwaszczania, uprawianych odmian i warunków pogodowych panujących w latach badań (tab. 6). Największe plony zebrano $\mathrm{z}$ obiektów pielęgnowanych mechaniczno-chemicznie, opryskiwanych mieszaninami herbicydów Command 480 EC + Afalon Dyspersyjny 450 SC i Stomp 400 SC + Afalon Dyspersyjny 450 SC. Plony były większe niż na obiekcie kontrolnym odchwaszczanym wyłącznie mechanicznie, odpowiednio o 16,43 i 13,59 t/ha. Uzyskane dane liczbowe wskazują na znaczącą rolę herbicydów wynikającą z redukcji zachwaszczenia. 
Tabela 2. Powietrznie sucha masa chwastów przed zwarciem rzędów ziemniaka $\left[\mathrm{g} / \mathrm{m}^{2}\right]$

Table 2. Air-dry matter of weeds before closing of potato rows $\left[\mathrm{g} / \mathrm{m}^{2}\right]$

\begin{tabular}{|c|c|c|c|c|c|c|c|}
\hline \multirow{2}{*}{$\begin{array}{l}\text { Sposób odchwaszczania } \\
\text { Weed control methods }\end{array}$} & \multicolumn{3}{|c|}{ Odmiana-Cultivar } & \multicolumn{3}{|c|}{ Lata - Years } & \multirow{2}{*}{$\begin{array}{c}\text { Średnio } \\
\text { Mean }\end{array}$} \\
\hline & Cekin & Satina & Tajfun & 2008 & 2009 & 2010 & \\
\hline 1. Obiekt kontrolny - Control object & 70,8 & 106,9 & 52,9 & 70,8 & 25,7 & 134,1 & 76,9 \\
\hline 2. Command $480 \mathrm{EC}$ & 37,8 & 55,1 & 34,4 & 49,3 & 16,4 & 61,5 & 42,4 \\
\hline 3. Command $480 \mathrm{EC}+$ Afalon Dyspersyjny $450 \mathrm{SC}$ & 26,0 & 30,4 & 22,1 & 36,6 & 11,0 & 31,0 & 26,2 \\
\hline 4. Stomp $400 \mathrm{SC}$ & 45,1 & 68,2 & 36,4 & 57,1 & 21,1 & 71,5 & 49,9 \\
\hline 5. Stomp $400 \mathrm{SC}+$ Afalon Dyspersyjny $450 \mathrm{SC}$ & 29,9 & 36,8 & 27,0 & 41,0 & 14,1 & 38,0 & 31,2 \\
\hline Średnio - Mean & 41,9 & 59,5 & 34,6 & 51,0 & 17,7 & 67,3 & 45,3 \\
\hline \multicolumn{7}{|l|}{$\operatorname{NIR}(0,05)-\operatorname{LSD}(0.05)$} & \\
\hline \multicolumn{7}{|l|}{ Lata - Years } & 12,8 \\
\hline \multicolumn{7}{|l|}{ Odmiana - Cultivar } & 12,8 \\
\hline \multicolumn{7}{|l|}{ Sposób odchwaszczania - Weed control method } & 4,7 \\
\hline \multicolumn{7}{|l|}{ Lata $\times$ odmiana - Years $\times$ cultivar } & r.n. \\
\hline \multicolumn{7}{|c|}{ Lata $\times$ sposób odchwaszczania - Years $\times$ weed control method } & 18,1 \\
\hline \multicolumn{7}{|c|}{ Odmiana $\times$ sposób odchwaszczania - Cultivar $\times$ weed control method } & 16,9 \\
\hline
\end{tabular}

r.n. - różnica nieistotna - not significant difference

Tabela 3. Powietrznie sucha masa chwastów przed zbiorem bulw ziemniaka $\left[\mathrm{g} / \mathrm{m}^{2}\right]$

Table 3. Air-dry matter of weeds before harvest of potato tubers $\left[\mathrm{g} / \mathrm{m}^{2}\right]$

\begin{tabular}{|c|c|c|c|c|c|c|c|}
\hline \multirow{2}{*}{$\begin{array}{l}\text { Sposób odchwaszczania } \\
\text { Weed control method }\end{array}$} & \multicolumn{3}{|c|}{ Odmiana - Cultivar } & \multicolumn{3}{|c|}{ Lata - Years } & \multirow{2}{*}{$\begin{array}{c}\text { Średnio } \\
\text { Mean }\end{array}$} \\
\hline & Cekin & Satina & Tajfun & 2008 & 2009 & 2010 & \\
\hline 1. Obiekt kontrolny - Control object & 168,3 & 224,5 & 121,0 & 212,2 & 27,1 & 274,4 & 171,2 \\
\hline 2. Command $480 \mathrm{EC}$ & 73,4 & 100,2 & 58,9 & 98,9 & 18,5 & 113,9 & 77,1 \\
\hline 3. Command $480 \mathrm{EC}+$ Afalon Dyspersyjny $450 \mathrm{SC}$ & 45,9 & 60,6 & 39,7 & 63,8 & 12,9 & 69,5 & 48,7 \\
\hline 4. Stomp $400 \mathrm{SC}$ & 114,7 & 130,3 & 75,6 & 115,6 & 22,8 & 182,2 & 106,9 \\
\hline 5. Stomp $400 \mathrm{SC}+$ Afalon Dyspersyjny $450 \mathrm{SC}$ & 59,6 & 82,3 & 48,2 & 80,7 & 14,4 & 95,0 & 63,4 \\
\hline Średnio - Mean & 92,4 & 119,6 & 68,7 & 114,2 & 19,1 & 147,0 & 93,5 \\
\hline \multicolumn{8}{|l|}{$\operatorname{NIR}(0,05)-\operatorname{LSD}(0.05)$} \\
\hline \multicolumn{7}{|l|}{ Lata - Years } & 18,1 \\
\hline \multicolumn{7}{|l|}{ Odmiana-Cultivar } & 18,1 \\
\hline \multicolumn{7}{|l|}{ Sposób odchwaszczania - Weed control method } & 20,7 \\
\hline \multicolumn{7}{|l|}{ Lata $\times$ odmiana - Years $\times$ cultivar } & 31,4 \\
\hline \multicolumn{7}{|c|}{ Lata $\times$ sposób odchwaszczania - Years $\times$ weed control method } & 35,9 \\
\hline \multicolumn{7}{|c|}{ Odmiana $\times$ sposób odchwaszczania - Cultivar $\times$ weed control method } & 30,7 \\
\hline
\end{tabular}

Tabela 4. Skuteczność zwalczania chwastów przed zwarciem rzędów ziemniaka

Table 4. Efficacy of weed control before row closing of the potato

\begin{tabular}{|c|c|c|c|c|c|c|c|}
\hline \multirow[t]{2}{*}{$\begin{array}{l}\text { Sposób odchwaszczania } \\
\text { Weed control method }\end{array}$} & \multicolumn{3}{|c|}{$\begin{array}{c}\text { Zniszczenie chwastów } \\
\text { Weed control [\%] } \\
\text { odmiana - cultivar }\end{array}$} & \multicolumn{3}{|c|}{ Lata - Years } & \multirow[t]{2}{*}{$\begin{array}{c}\text { Średnio } \\
\text { Mean }\end{array}$} \\
\hline & Cekin & Satina & Tajfun & 2008 & 2009 & 2010 & \\
\hline 1. Obiekt kontrolny - Control object $\left[\mathrm{g} / \mathrm{m}^{2}\right]$ & 70,8 & 106,9 & 52,9 & 70,8 & 25,7 & 134,1 & 76,9 \\
\hline 2. Command $480 \mathrm{EC}$ & 46,6 & 52,2 & 35,0 & 30,4 & 36,2 & 54,1 & 42,4 \\
\hline 3. Command $480 \mathrm{EC}+$ Afalon Dyspersyjny $450 \mathrm{SC}$ & 63,3 & 71,6 & 58,2 & 48,3 & 57,2 & 76,9 & 62,5 \\
\hline 4. Stomp $400 \mathrm{SC}$ & 36,3 & 36,2 & 31,2 & 19,3 & 17,9 & 46,7 & 31,3 \\
\hline 5. Stomp $400 \mathrm{SC}+$ Afalon Dyspersyjny $450 \mathrm{SC}$ & 57,8 & 65,6 & 49,0 & 42,0 & 45,1 & 71,7 & 55,2 \\
\hline Średnio - Mean & 51,0 & 56,4 & 43,3 & 35,0 & 39,1 & 62,3 & 47,9 \\
\hline
\end{tabular}


Tabela 5. Skuteczność zwalczania chwastów przed zbiorem bulw ziemniaka

Table 5. Efficacy of weed control before harvest of the potato

\begin{tabular}{|c|c|c|c|c|c|c|c|}
\hline \multirow{3}{*}{$\begin{array}{l}\text { Sposób odchwaszczania } \\
\text { Weed control method }\end{array}$} & \multirow{2}{*}{\multicolumn{3}{|c|}{$\begin{array}{c}\text { Zniszczenie chwastów } \\
\text { Weed control }[\%]\end{array}$}} & \multirow{2}{*}{\multicolumn{3}{|c|}{ Lata - Years }} & \multirow{3}{*}{$\begin{array}{l}\text { Średnio } \\
\text { Mean }\end{array}$} \\
\hline & & & & & & & \\
\hline & Cekin & Satina & Tajfun & 2008 & 2009 & 2010 & \\
\hline 1. Obiekt kontrolny - Control object $\left[\mathrm{g} / \mathrm{m}^{2}\right]$ & 168,3 & 224,5 & 121,0 & 212,2 & 27,1 & 274,4 & 171,2 \\
\hline 2. Command $480 \mathrm{EC}$ & 56,4 & 55,4 & 51,3 & 53,4 & 31,7 & 58,5 & 51,1 \\
\hline 3. Command $480 \mathrm{EC}+$ Afalon Dyspersyjny $450 \mathrm{SC}$ & 72,7 & 73,0 & 67,2 & 69,9 & 52,4 & 74,7 & 68,3 \\
\hline 4. Stomp $400 \mathrm{SC}$ & 31,8 & 41,9 & 37,5 & 45,5 & 15,9 & 33,6 & 34,4 \\
\hline 5. Stomp $400 \mathrm{SC}+$ Afalon Dyspersyjny $450 \mathrm{SC}$ & 64,6 & 63,3 & 60,2 & 62,0 & 46,0 & 65,4 & 60,3 \\
\hline Średnio - Mean & 56,4 & 58,4 & 54,0 & 57,7 & 36,7 & 58,0 & 53,5 \\
\hline
\end{tabular}

Tabela 6. Plon bulw frakcji handlowej [t/ha]

Table 6. The yield of trade fraction tubers $[\mathrm{t} / \mathrm{ha}]$

\begin{tabular}{|c|c|c|c|c|c|c|c|}
\hline \multirow{2}{*}{$\begin{array}{l}\text { Sposób odchwaszczania } \\
\text { Weed control method }\end{array}$} & \multicolumn{3}{|c|}{ Odmiana-Cultivar } & \multicolumn{3}{|c|}{ Lata - Years } & \multirow{2}{*}{$\begin{array}{c}\text { Średnio } \\
\text { Mean }\end{array}$} \\
\hline & Cekin & Satina & Tajfun & 2008 & 2009 & 2010 & \\
\hline 1. Obiekt kontrolny - Control object & 24,83 & 21,81 & 27,99 & 32,54 & 19,40 & 22,69 & 24,88 \\
\hline 2. Command $480 \mathrm{EC}$ & 35,47 & 30,37 & 38,18 & 43,63 & 24,98 & 35,41 & 34,67 \\
\hline 3. Command $480 \mathrm{EC}+$ Afalon Dyspersyjny $450 \mathrm{SC}$ & 41,64 & 38,40 & 43,88 & 49,68 & 33,03 & 41,21 & 41,31 \\
\hline 4. Stomp $400 \mathrm{SC}$ & 32,11 & 27,64 & 37,20 & 42,30 & 23,23 & 31,42 & 32,32 \\
\hline 5. Stomp $400 \mathrm{SC}+$ Afalon Dyspersyjny $450 \mathrm{SC}$ & 39,53 & 33,66 & 42,23 & 48,41 & 29,99 & 37,02 & 38,47 \\
\hline Średnio - Mean & 34,72 & 30,37 & 37,90 & 43,31 & 26,13 & 33,55 & 34,33 \\
\hline \multicolumn{8}{|l|}{$\operatorname{NIR}(0,05)-\operatorname{LSD}(0.05)$} \\
\hline \multicolumn{7}{|l|}{ Lata - Years } & 0,55 \\
\hline \multicolumn{7}{|l|}{ Odmiana - Cultivar } & 0,55 \\
\hline \multicolumn{7}{|l|}{ Sposób odchwaszczania - Weed control method } & 0,91 \\
\hline \multicolumn{7}{|l|}{ Lata $\times$ odmiana - Years $\times$ cultivar } & 0,95 \\
\hline \multicolumn{7}{|c|}{ Lata $\times$ sposób odchwaszczania - Years $\times$ weed control method } & 1,59 \\
\hline \multicolumn{7}{|c|}{ Odmiana $\times$ sposób odchwaszczania - Cultivar $\times$ weed control method } & 1,36 \\
\hline
\end{tabular}

Zwiększenie plonu bulw w stosunku do poletek kontrolnych uzyskali także Urbanowicz (2008, 2010), Gugała i Zarzecka (2009) oraz Krzysztofik i wsp. (2009). Plon ziemniaka różnił się istotnie $\mathrm{w}$ latach prowadzenia doświadczenia. Największy średni plon frakcji handlowej $(43,31 \mathrm{t} / \mathrm{ha})$ otrzymano w 2008 roku, a najmniejszy (26,13 t/ha) w 2009 roku. Tak znaczne różnice w plonowaniu wynikały $\mathrm{z}$ ilości opadów i ich rozkładu oraz warunków termicznych w poszczególnych miesiącach wegetacji. Najkorzystniejszy dla plonowania okazał się 2008 rok, w którym temperatura powietrza była najbardziej zbliżona do panującej w okresie wieloletnim, opady były dość równomiernie rozłożone, a współczynnik hydrotermiczny stabilny. O istotnym wpływie warunków wilgotnościowo-termicznych na plon i jego strukturę donoszą Szewczuk (2009) i Zarzyńska (2010). Również Lahlou i wsp. (2003) wykazali, że susza podczas wegetacji ziemniaka redukowała plon bulw o 11 do 53\%. Kalbarczyk (1999) na podstawie wieloletnich badań stwierdził, że plon ziemniaka zmniejszał się zarówno przy niedostatecznym, jak i nadmiernym uwilgotnieniu gleby. Wykazano inter- akcję lat z czynnikami doświadczenia, która potwierdza, że plonowanie odmian oraz efekty odchwaszczania różnicowały warunki pogodowe w latach badań.

\section{Wnioski / Conclusions}

1. Z badanych sposobów pielęgnacji największą skutecznością w ograniczaniu liczby chwastów odznaczała się pielęgnacja mechaniczno-chemiczna $\mathrm{z}$ wykorzystaniem mieszaniny herbicydów Command $480 \mathrm{EC}+$ Afalon Dyspersyjny 450 SC.

2. Herbicydy zastosowane na plantacji ziemniaka, w wyniku eliminacji konkurencji chwastów, przyczyniły się zwiększenia plonu bulw o 7,44 do 16,43 t/ha w stosunku do obiektu kontrolnego pielęgnowanego mechanicznie.

3. Wyniki badań potwierdziły istotny wpływ odmian i warunków wilgotnościowo-termicznych panujących podczas wegetacji na plon bulw frakcji handlowej ziemniaka. 


\section{Literatura / References}

Bac S., Koźmiński Cz., Rojek M. 1998. Agrometerologia. Państwowe Wydawnictwo Naukowe, Warszawa, 274 ss.

Badowski M., Domaradzki K., Filipiak K., Franek M., Gołębiowska H., Kieloch R., Kucharski M., Rola H., Rola J., Sadowski J., Sekutowski T., Zawerbny T. 2001. Metodyka doświadczeń biologicznej oceny herbicydów, bioleguratorów i adiuwantów. Cz. 1. Doświadczenia polowe. Instytut Uprawy Nawożenia i Gleboznastwa, Wrocław, 167 ss.

Fernandez-Quintanilla C., Quadranti M., Kudsk P., Barberi P. 2008. Which future for weed science? Weed Research 48: $297-301$.

Gugała M., Zarzecka K. 2009. Ocena skuteczności herbicydów w uprawie ziemniaka. [Evaluation the effectiveness of herbicides in potato cultivation]. Biuletyn Instytutu Hodowli i Aklimatyzacji Roślin 251: 225-234.

Gugała M., Zarzecka K., Zadrożniak B. 2010. Wpływ adiuwantów na plonowanie i ograniczenie zachwaszczenia na plantacji ziemniaka. [An effect of adjuvants on potato yielding and limiting weed infestation in potato stands]. Biuletyn Instytutu Hodowli i Aklimatyzacji Roślin 255: 47-57.

Kalbarczyk R. 1999. Wpływ czynników agrometeorologicznych na plonowanie ziemniaków w województwie lubelskim. Zeszyty Naukowe Akademii Rolniczej w Szczecinie 202, Agricultura 79: 91-98.

Krzysztofik B., Marks N., Baran D. 2009. Wpływ wybranych czynników agrotechnicznych na ilościowe cechy plonu bulw ziemniaka. Inżynieria Rolnicza 5 (114): 123-129.

Lahlou O., Ouattar S., Ledent J.F. 2003. The effect of drought and cultivar on growth parameters, yield and yield components of potato. Agronomie 23 (3): 257-268.

Praczyk T., Skrzypczak G. 2011. Stan aktualny i kierunki rozwoju herbologii. [The current state and directions of weed science development]. Progress in Plant Protection/Postępy w Ochronie Roślin 51 (1): 354-363.

Pytlarz-Kozicka M. 2002. Wpływ sposobów pielęgnowania na wysokość i jakość plonów ziemniaka. Zeszyty Problemowe Postępów Nauk Rolniczych 489: 147-155.

Rębarz K., Borówczak F. 2009. Wpływ deszczowania, technologii uprawy i nawożenia azotem na zachwaszczenie ziemniaków. Fragmenta Agronomica 26 (4): 150-159.

Rozporządzenie Ministra Rolnictwa i Rozwoju Wsi w sprawie szczegółowych wymagań w zakresie jakości handlowej ziemniaków. 2003. (Dz. U. nr 194 poz. 1900 z 2003 roku).

Roztropowicz S., Czerko Z., Głuska A., Goliszewski W., Gruczek T., Lis B., Lutomirska B., Nowacki W., Wierzejska-Bujakowska A., Zarzyńska K., Zgórska K. 1999. Metodyka obserwacji pomiarów i pobierania prób w agrotechnicznych doświadczeniach z ziemniakiem. Instytut Hodowli i Aklimatyzacji Roślin, Jadwisin, 50 ss.

Szewczuk Cz. 2009. Wpływ dokarmniania dolistnego na plon bulw ziemniaka. Annales Universitatis Mariae Curie-Skłodowska, Sectio E, Agricultura 64 (1): 7-12.

Urbanowicz J. 2008. Ocena chwastobójczego działania herbicydu Flumioksazin 50 WP w uprawie ziemniaka. [Assessment of Flumioksazin on weed control in potato crop]. Progress in Plant Protection/Postępy w Ochronie Roślin 48 (2): 691-694.

Urbanowicz J. 2010. Wpływ powschodowego stosowania metrybuzyny na plon wybranych odmian ziemniaka. [Influence of metribuzin applied post emergence on yield of selected potato cultivars]. Progress in Plant Protection/Postępy w Ochronie Roślin 50 (2): $837-841$.

Zarzecka K., Gugała M., Mystkowska I., Baranowska A. 2014. Wpływ herbicydów i ich mieszanin na wielkość plonu ubocznego bulw ziemniaka. Acta Agrophysica 21 (3): 375-385.

Zarzyńska K. 2010. Struktura plonu bulw ziemniaków uprawianych w systemie ekologicznym i integrowanym w różnych warunkach środowiskowych. Journal of Research and Applications in Agricultural Engineering 55 (4): 181-184. 